- News \& Views •

\title{
Chen-Chao Koo and the Early Numerical Weather Prediction Experiments in China
}

\author{
Jianhua $\mathrm{LU}^{* 1,2}$ \\ ${ }^{1}$ School of Atmospheric Sciences \& Guangdong Province Key Laboratory for Climate Change and Natural Disaster \\ Studies, Sun Yat-sen University, Zhuhai 519082, China \\ ${ }^{2}$ Southern Marine Science and Engineering Guangdong Laboratory (Zhuhai), Zhuhai 519082, China
}

(Received 19 December 2020; revised 20 January 2021; accepted 26 January 2021)

\begin{abstract}
Although the first successful numerical weather prediction (NWP) project led by Charney and von Neumann is widely known, little is known by the international community about the development of NWP during the 1950s in China. Here, a detailed historical perspective on the early NWP experiments in China is provided. The leadership in NWP of the late Professor Chen-Chao Koo, a protégé of C. G. Rossby at the University of Stockholm during the late 1940s and a key leader of modern meteorology (particularly of atmospheric dynamics and physics) in China during the 1950s-70s, is highlighted. The unique contributions to NWP by Koo and his students, such as the ideas of formulating NWP as an "evolution" problem, in which the past data over multiple time steps are utilized, rather than an initial-value problem, and on the cybernetic aspects of atmospheric processes, i.e., regarding the motion of the atmosphere at various time scales as an optimal control system, are also emphasized.
\end{abstract}

Key words: Chen-Chao Koo, Numerical Weather Prediction, evolution problem, cybernetic aspects of atmospheric processes

Citation: Lu, J. H., 2021: Chen-Chao Koo and the early numerical weather prediction experiments in China. Adv. Atmos. Sci., 38(5), 707-716, https://doi.org/10.1007/s00376-021-0268-y.

\section{Introduction}

Soon after the first successful numerical weather prediction (NWP) experiment led by Charney and von Neumann (Charney et al., 1950; Harper, 2008), similar experiments were conducted in several other countries, mainly in European countries and also in Japan, and the first operational NWP system was established in Sweden in 1954 (Persson, 2005a, b, c). While operational weather forecasting still used the traditional graphical (weather-chart) method at that time, these early NWP experiments, often based on simplified one- or two-layer quasigeostrophic equations over limited areas, initiated a quiet revolution in the practice of weather forecasting across the world over the past seventy years (Bauer et al., 2015). Harper (2008) vividly described with details from available archives the first NWP experiment and the key roles played by Charney, von Neumann, and Rossby. The later development in NWP has been thoroughly reviewed in Persson (2005a, b, c), Benjamin et al. (2018), and Randall et al. (2018).

So far, relatively little is known by the international research community about the early development, particularly the detailed evolution, of NWP in China, although Chinese scientists had started their NWP research as early as in the 1950s and contributed uniquely to the symphony of NWP around the world. Blumen and Washington (1973) analyzed the development of NWP in China until 1966 mainly thorough the papers that were translated into English, but given the near isolation between China and the U.S. at that time, they were not able to describe its evolution and to point out the role of its key leader in such an evolution. Persson (2005b) did briefly mention the early NWP experiments in China, but his description was mainly based on Blumen and Washington (1973). Therefore, the intention of this paper is to provide a detailed description of the NWP experiments led by Chen-Chao Koo, focusing on the early stage until 1959, while briefly mentioning the later developments that have been previously reviewed by other authors.

\footnotetext{
* Corresponding author: Jianhua LU

Email: lvjianhua@mail.sysu.edu.cn
} 


\section{Prelude}

Charney's seminal paper "On a Physical Basis for Numerical Prediction of Large-Scale Motions in the Atmosphere" (Charney, 1949) described in detail the theoretical basis for the NWP project led by him and von Neumann, which eventually proved very successful and initiated the era of the "quiet revolution" of NWP (Bauer et al., 2015). Readers may refer to Harper (2008) and Randall et al. (2018) for detailed description of the first NWP experiment. While providing the formula of the influence function $\left[I_{\mathrm{a}}^{2}(x, t)\right]$, Charney added a note stating that "this formula has been obtained independently by $\mathrm{C}$. C. Koo (personal communication)" (Charney, 1949). This independent derivation was later published as a correspondence in pages 163-164 of the seventh volume of the Journal of Meteorology, with the title "An iterative relation of the influence function in numerical forecasting" (Koo, 1950). The author Chen-Chao Koo (Zhenchao Gu in current pronunciation, see Table 2 for a brief biographic sketch) had been a doctorate student of C. G. Rossby at the University of Stockholm since 1947. In the beginning of the correspondence, Koo stated "[I]n a forthcoming paper (Ed. note: since published), Charney mentions and makes use of an iterative relation of the influence function which was also discovered independently by me in preparing a 48-hour prognostic chart by an extension of his numerical method. As the formula is a very practical one and no proof is given in his paper, I would like to present my proofs here" (Koo, 1950).

It is obvious that even before the papers of Charney and Eliassen (1949) and Charney (1949) were published, Charney's manuscripts had been circulated in Rossby's research group in Stockholm, confirming the statement of Harper (2008) about “Rossby's aggressive sharing of the Charney-Eliassen paper with the 'younger people' (graduate students and post-doctoral researchers, presumably) ..." (p. 134, Harper, 2008). As Harper (2008) put it very clearly from the available archives, Rossby, while dividing his time between USA (Chicago) and Sweden (Stockholm) in this period, had been crucial in providing personnel, technical, and morale support to Charney's NWP project in Princeton, and so, as one of Rossby's protégés, Koo's interest in Charney's project was not surprising at all. Indeed, as seen from his later publication, Koo did write in 1949 an unpublished manuscript, “48-hr prognostic 500-mb charts prepared by Charney's numerical method of forecasting".

Under Rossby's supervision, Koo was dedicated to his PhD studies in NWP. However, he decided to abandon his studies several months before his $\mathrm{PhD}$ defense, because he was so eager to serve the newly founded People's Republic of China. With Rossby's help, Koo returned to China in the spring of 1950. Soon after his return to China, Koo was named as one of two joint directors of the Section of Synoptic and Dynamic Meteorology in the newly established Institute of Geophysics and Meteorology (IGM) in the Chinese Academy of Sciences (CAS). The other director was T.C. Yeh (Duzheng Ye), who was Rossby's protégé in Chicago and returned to China in 1950, several months after Koo returned from Sweden. Since there was not yet an established operational meteorological service in China, Koo was soon named as the director of the Joint Center for Weather Forecasting under the Central Meteorological Administration (CMA) with support from the IGM/CAS, and hence Koo was one of the key figures responsible for the establishment of a modern operational weather forecasting system and the training of weather forecasters at the national level.

After Koo's return to the IGM/CAS in 1955, he and T.C. Yeh led the advancement of dynamic meteorology within the institute by conducting theoretical research on general circulation of the atmosphere, both globally and over East Asia, and by establishing Tibetan Plateau Meteorology (Blumen and Washington, 1973; Lu and Schneider, 2017). After 1955, Koo became responsible for initiating the development of new atmospheric science research fields, including NWP, cloud physics, atmospheric turbulence, weather modification, and atmospheric cybernetics, both through his own research and by training a whole generation of young scientists at the institute. This continued until he unfortunately passed away in 1976 of a long-term disease, caused by HBV infection years ago while he was helping a local peasant by blood transfusion, at the age of 56. T.C. Yeh, Koo's life-long colleague since 1950, stated that "Koo had been the most active and smartest atmospheric scientist in China from the 1950s to 1970s" (Zhou, 2006).

\section{Preparation}

As previously stated, the period of 1950-55 witnessed rapid growth of the interest in NWP spread over several countries after the success of Charney's project. The Princeton group continued their experiments beyond the initial experiment based on a barotropic model, but other research groups, including the Stockholm and Japanese groups, also began reporting their NWP results during that period. Of note, Rossby's Stockholm group performed their NWP experiments on BESK (a Swedish computer), making operational forecasts (Persson, 2005a; Harper, 2008; Bengtsson et al., 2015).

Indeed, the development of the NWP experiments and models under Koo's leadership initiated even before his return in 1955 to the IGM/CAS. While Koo was leading the establishment of an operational weather forecasting system in CMA during this period, he must have been paying close attention to the development of NWP all over the world as well. In 1954, Koo had started to prepare a thorough review summarizing the developments of NWP methods and models across the world. The review, entitled "Hydrodynamical methods for forecasting large-scale aerological temperature-pressure fields," which was eventually published in Acta Meteorologica Sinica during 1955 as two parts, was used as the teaching material 
for the NWP team Koo organized starting in 1956 (Koo, 1955a, b). Also in 1954, Koo started advising Tung-Hsien Liao, a young meteorologist working in the Central Meteorological Observatory. Koo taught Tung-Hsien Liao to apply the graphical method developed by Fjørtoft (1952) to a modified Eliassen's two-parameter model (Eliassen, 1952) in the numerical prediction of cold surge cases, and despite there being no computer available in China at the time, they obtained quite good results (Liao, 1956). Almost immediately after Koo finished his duties at the CMA and returned to the IGM/CAS in 1955, he initiated a NWP project under the support of the director-general, Jeou-Jang Jaw. Based on his experience as part of Rossby's Stockholm group and his own interest in and previous research on NWP, Koo was possibly the best candidate to lead the NWP project. Additionally, with his leading role in establishing China's operational weather forecasting system during recent years, Koo was prepared to help directly link the development of the models with operational weather forecasting.

The difficulties Koo had to face were daunting, however. Almost none of the atmospheric scientists in China beyond himself had any experience in NWP, and it was unknown when the first computer would become available in China. Koo insisted that the need for NWP in China was urgent from the viewpoints of both meteorological science and its application, and hence the NWP project must not be delayed until the computer was ready. Koo organized a team by recruiting several students soon after they graduated from various universities in China to join the Institute of Geophysics and Meteorology and the CMA. These participants of the NWP team at the Institute of Geophysics, who were trained in developing the NWP model, included: Xiong-Shan Chen and You-Fen Xu (graduates from Nanjing University) and Rui-Zhi Liu and Li-Ren Ji (graduates from Peking University). The participants of the NWP team at the CMA included: Tung-Hsien Liao (graduate from Tsinghua University), Ji-Fan Chou (graduate from Peking University), Xiang-Yun Liao (graduate from Nanjing University), and Zong-Hao Wang (graduate from Wuhan University).

Li-Ren Ji and Tung-Hsien Liao, two members of the NWP team led by Koo, stated in their memoir on Koo as the pioneer and founding father of NWP in China, that Koo collected and shared with the NWP team the most state-of-the-art papers on NWP from the western countries, the Soviet Union, and Japan. Koo also had the NWP team translate the book by Kibel on NWP (Kibel, 1957) into Chinese in order to fully understand the two schools of NWP from different parts of the world and then develop their own method.

\section{The NWP experiments based on the graphical method}

Even before the publication of Liao (1956), Koo had fully realized the necessity of including baroclinic effects in NWP models. Koo thoroughly reviewed (Koo, 1955b) the existing baroclinic models, from the relatively simple $2 \frac{1}{2} 2$-dimensional model (Fjørtoft, 1952) to the two-level geostrophic models of Phillips (1951) and Charney and Phillips (1953), as well as other models from the UK, Sweden, and Japan. Soon after, in 1957, Koo and two colleagues published the results of NWP forecasting experiments based on geostrophic two-parameter and three-parameter models. They concluded that the result from the two-parameter model (Fig. 1), in which the baroclinic effects are partly included, is quite good but fails to forecast the blocking situation (Koo et al, 1957a), but the blocking may be predicted using a three-parameter model in which the baroclinic effects are better represented by including the vertical difference of thermal advection (Koo et al., 1957b).

Given the important influence of specific topography, such as the Tibetan Plateau, on the development of weather systems in China, Koo and his students developed methods of considering the kinematic boundary condition of topography in a quasi-geostrophic model (Chih et al., 1958) and also studied the vertical structure of synoptic perturbation over the Tianshan-Altai mountains in a stratified atmosphere (Koo and Chen, 1957).

Meanwhile, Y-S Chen and three other members of Koo's NWP team developed a two-layer model in isentropic coordinates, which was based on the principle of potential vorticity conservation and used the Montgomery streamfunction as the prognostic variable (Chen et al., 1957), which was similar to the approach of Charney and Phillips (1953) but with refined boundary conditions. By employing the graphical method, Chen et al. (1957) used their model to make a 12-hour forecast of a strong frontal case, resulting in better forecasting capability for such a situation compared to a two-layer model in pressure coordinates, though they realized that the treatment of boundary conditions was quite difficult in an isentropic model.

While developing models during this period, Chen-Chao Koo also paid attention to the numerical algorithms. Koo (1957b) discussed how to use numerical diffusion in damping small-scale waves, and he pointed out that Richardson's failure might be attributed to the too weak smoothing in his calculation. Koo (1958c) reported the best approximate solutions for finite-difference Poisson equation by using a double-harmonic series solution.

\section{NWP as an "evolution" problem and the use of past data}

Although NWP modeling was treated as an "initial-value" problem, the routine weather forecasting at that time was basically an "evolution" problem based on the subjective judgment of the forecaster by using the past data. The two approaches may have seemed totally different, but Chen-Chao Koo thought that they might just be equivalent with each other given their similar success in pragmatic forecasting. Koo elaborated in Koo (1958a, Fig. 2a) a theoretical framework 
(a)

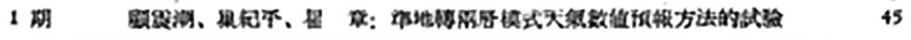
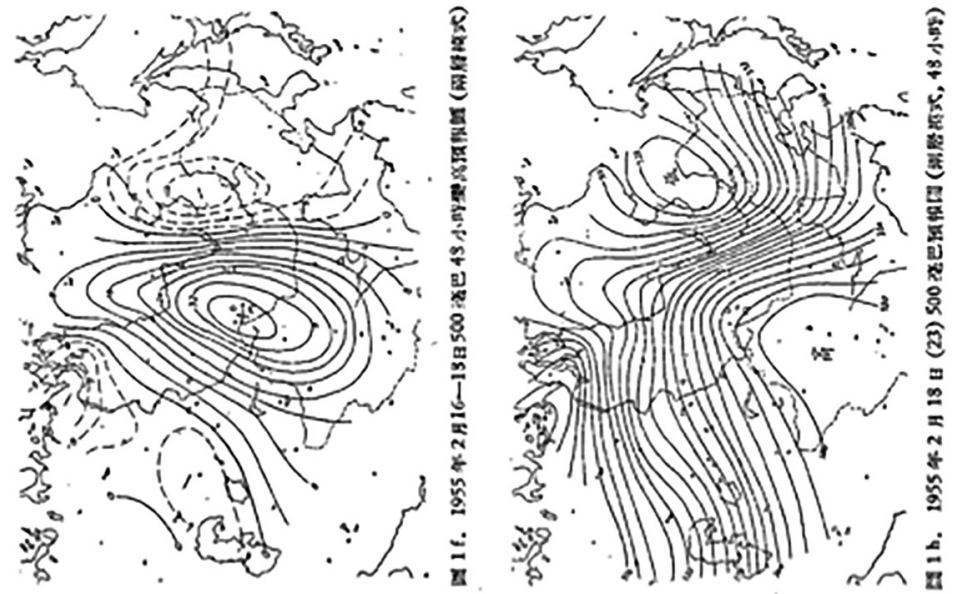

(b)

\section{A TEST FOR 24 AND 48.HR NUMERICAL FORECASTING WITH A QUASI-GEOSTOPHIC TWO-PARAMETER MODEL}

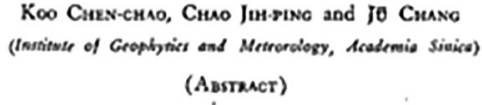

Some 24 and 48 -hr numerical forecasts for $500 \mathrm{mb}$ topography over a parr of Asia afe prepared by graphical method with a quasi-grostrophic two-parameter model. The result is in general rather good, but for the cax of bloxking, the nxgative beightschange center south, to the position of the bloxking high is not forecasted and thus the blocking high does noe appear on our prognostic chart. This is due to the neglection of the $500 \mathrm{mb}$ divergence which is of importance for the major development of weather systems on $500 \mathrm{mb}$ level. Some of the ertors is attributed to the Fiprtoft's formula used for the graphical integration of Poisson equation.

Fig. 1. 48-hour forecasting of height tendency and height at $500 \mathrm{hPa}$ (a) and the abstract (b) of Koo et al. (1957a).

for revealing the equivalency of NWP based on the quasi-geostrophic height tendency equation (i.e., the initial-value formulation) and the routine weather forecasting based on the evolution of surface weather conditions (pressure and temperature). The English version of Koo (1958a) was included in the now classic Rossby Memorial Volume (Bolin, 1959), in the "weather forecasting" section with other contributions from T. Bergeron, G. P. Cressman, K. Hinkelmann, and N. A. Phillips. In the paper, Koo said,

“...[t]he equivalency of these two different formulations [Note: the initial-value problem formulation and the evolution problem formulation] has some very interesting implications. Physically it means that as the evolution of the $\boldsymbol{\Phi}$ and $\boldsymbol{T}$ fields is nothing but the result of the baroclinic development of the three-dimensional pressure and temperature fields of the atmosphere, the evolution of the surface fields necessarily reflect and imply the baroclinic structure of the three-dimensional atmospheric motion. Roughly speaking, for the large scale motions a series of weather maps ( $\boldsymbol{\Phi}$ and $\boldsymbol{T}$ fields) at different time intervals for the same level is theoretically equivalent to a series of weather maps for different levels at the same instant. ..." (Koo, 1959a).

Three months after the publication of Koo (1958a), Chen-Chao Koo further envisaged the possibility of treating numerical weather forecasting as an evolution problem in his paper "On the utilization of past data in numerical weather forecasting" (Koo, 1958b; Fig. 2b). After noticing the mismatch between the equations of NWP models and the boundary and initial conditions that the observations may provide for the models, Chen-Chao Koo pointed out that it is essential for the NWP models to utilize available past data as much as possible in order to find the best form of integrating numerical model equations, provide the best conditions of determining the solution to the equations, and obtain the optimal forecasting solution (Koo, 1958b). Chen-Chao Koo suggested two possibilities for utilizing past data in numerical forecasting: either weather forecasting may be formulated as an evolution problem in which the past data are directly utilized, or the past data may be partly utilized in a transformed initial-value problem which, with some variables in the governing equations being 
(a)

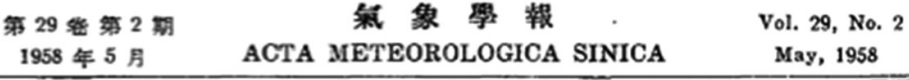

\title{
作䉆初値問題的天氣形勢數値預報與由地面天氣 歴史演變作預報的等値性*
}

\author{
原震湖

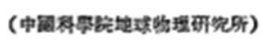

势 要

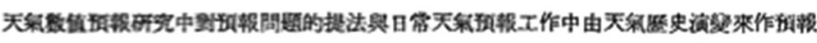

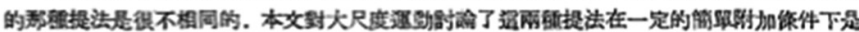

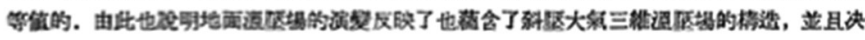

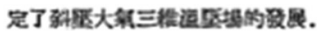

ON THE EQUIVALENCY OF FORMULATIONS OF WEATHER FORECASTING AS AN INITIAL VALUE PROBLEM AND AS AN "EVOLUTION" PROBLEM

Koo Chen-cano

(Institute of Geophysice and Meteorology, Academia Sinica)

Asstruct

Weather forecasting is formulated as an initial value problem in the work of numerical forecasting, while in the routine forecasting in the conventional way it is formulated as, an 'evolution' problem of weathor process, especially way it is formulated as, an 'evolution' problem of weathor process, especially that on certain speciffe level. It is shown in this paper that for large-seale motion these two different formulations are in fact equivalent under certain trivial conditions. It is also pointed out that for large-scale motion the threedimensional structure of the baroclinie atmosphere at certain moment is temperature fields at certain level before and after that moment.

(b)

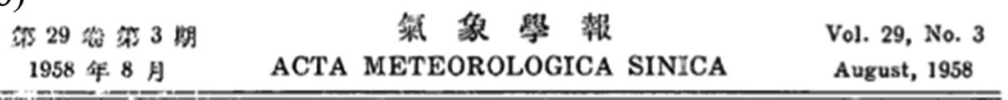

天氣數値預報中過去資料的使用問題*

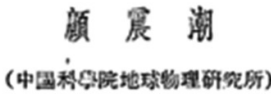

ON THE UTILIZATION OF PAST DATA IN NUMERICAL WEATHER FORECASTING

Koo Chen-chao

(Inetitute of Geophysios and. Meteorology, Aeademia Siniea)

\section{A вstract}

Until now, past data are not utilized in numerical weather forecasting owing to the particular formulations of the problem. It is pointed out in this paper that the condition for solution, formed by whole set of available meteorological data, is not competible to the general system of weather equations. Thus it is neccessary to study the best way of formulation of the problem using the available meteorological data as much as possible in the condition for solution, in order to obtain the optimum way of forecasting. Two possibilities are given. Firstly, it is shown that under certain condition, weather forecasting may be formulated as an evolution problem, in which the past data are utilized. Secondly, past data could also be partly utilized in an initial value problem in which the system of weather equations, with certain meteorological variables eliminated, contain higher order time derivatives. The significance of these formulations is discussed.

Fig. 2. (a) The title and abstract of Koo (1958a). (b) The title and abstract of Koo (1958b). 
eliminated, contains high order time derivatives of the remaining variables.

Koo's ideas on the approach of NWP were clearly quite different from treating NWP as an initial-value problem, proven successful by Charney's experiment, and also different from the objective analysis (or more generally data assimilation) methods developed during 1950-60s for obtaining better initial conditions for NWP models. Indeed, Sasaki (1970) developed a variational data assimilation method, which takes the past data (or the temporal distribution of observations as mentioned in Lewis and Lakshmivarahan, 2008) into consideration, though the numerical prediction was still based on the initial-value problem formulation.

Koo's idea on formulating numerical forecasting as an evolution problem was fulfilled by Ge-fen Chou (Ji-Fan Chou), a CMA-based member of Koo's NWP team, in 1962 by reformulating the governing differential equations into a functional-variational problem with the solution being so-called "generalized solution". Although the method was developed in 1962, Chou did not publish the results immediately under Koo's suggestion, and the final publication of the results, with the non-divergent barotropic model and quasi-geostrophic baroclinic model as examples, was delayed until 1974 (Chou, 1974), due to the nearly complete cessation of scientific publications in China after 1966. The title of Chou (1974), "A problem of using past data in numerical weather forecasting", clearly shows that Chou's method was inspired by Chen-Chao Koo's original thinking on the issue.

\section{Epilogue}

All of the publications in Table 1 [also attached as Fig. S1 in the electronic supplementary material (ESM) for including the original titles in Chinese] were published before the first computer-based numerical weather forecasting in 1959, which was conducted soon after the computer made by the CAS was available. The success of this first-time computerbased NWP experiment clearly depended on the far-reaching vision, superb organizational capabilities, and scientific insight and understanding of Chen-Chao Koo, who organized and trained an NWP team and led talented young scientists into the frontier of numerical weather forecasting in a new-born nation with very limited existing resources.

In addition to providing training for the NWP group team members, Chen-Chao Koo also sent Yong-Ti Chu and ShiaoPing Chou (Xiao-Ping Zhou), two young scientists at the IGM/CAS, to join Kibel's numerical weather forecast group as graduate students to study the numerical prediction of long-range weather and convection, respectively. Chen-Chao Koo also recommended Qing-Cun Zeng, a graduate from Peking University, to study NWP under the supervision of Kibel. Given the unique approaches of NWP developed in the Soviet Union during the late 1950s (Phillips et al., 1960) and the isolation of China from western countries, Koo's suggestions were indeed very crucial to the future development of atmospheric models in China.

C. T. Tseng (Qing-Cun Zeng) invented a semi-implicit (called "semi-explicit" by Tseng at first) scheme and succeeded in baroclinic primitive-equation-based numerical weather forecasting in 1961 while he was in the Soviet Union (Tseng, 1961). After that, he returned to the IGM (now the Institute of Atmospheric Physics, IAP) in CAS. Qing-Cun Zeng published a thorough theoretical monograph on the mathematical-physical basis of NWP (Zeng, 1979a) and has led the development of climate and earth system modeling at the institute since the 1980s. Based on E. N. Bolinova's barotropic model, Y.T. Chu developed a three-level (1000-, 500-, and 300-hPa) nonlinear model in spherical coordinates to investigate the effect of topography on a 24-hour forecast (Chu, 1961).

During the 1960s, there were quite a lot of multi-level baroclinic modeling studies at the IGM/CAS, mainly focused on long-range forecasting and also on large- and meso-scale atmospheric dynamics. As mentioned in Blumen and Washington (1973), a series of papers were collected in a monograph prepared by the Numerical Weather Prediction Group of the IGM (Koo et al., 1961), and the monograph formed a major new impetus to an organized research effort in atmospheric dynamics in China during the 1960s. Except for numerical weather forecasting, the numerical models developed at the IGM/CAS during the 1960s were also extensively used in the investigation of the dynamics of general circulation, the effects of topography and thermal heating on stationary waves, and the interaction between wavy mean flow and transient eddies, and hence contributed essentially to the flourishing of atmospheric dynamics in China before 1966 (Blumen and Washington, 1973; Lu and Schneider, 2017). Readers may refer to Blumen and Washington (1973) for more details on the development of atmospheric dynamics and numerical weather forecasting before 1966.

Of particular importance, in the publication entitled "Cybernetic aspects of atmospheric processes" (Koo, 1962) ChenChao Koo proposed that the motion of atmosphere at various time scales in response to solar radiation may be regarded as an optimal control system. He also examined in detail the linear and non-linear feedbacks in a forced, two-layer quasi-geostrophic model in Koo (1962). He correctly pointed out that some aspects of atmospheric variation, such as the mean annual cycles of $500 \mathrm{hPa}$ height and temperature and of surface temperature, behave like a quasi-linear system, while mediumrange variations are nonlinear and asynchronous excitations which may also give rise to a periodical response in a non-linear system. In fact, Koo's ideas on the cybernetic aspect of atmospheric processes may be very helpful in understanding the natural and anthropogenic variations of climate change. 


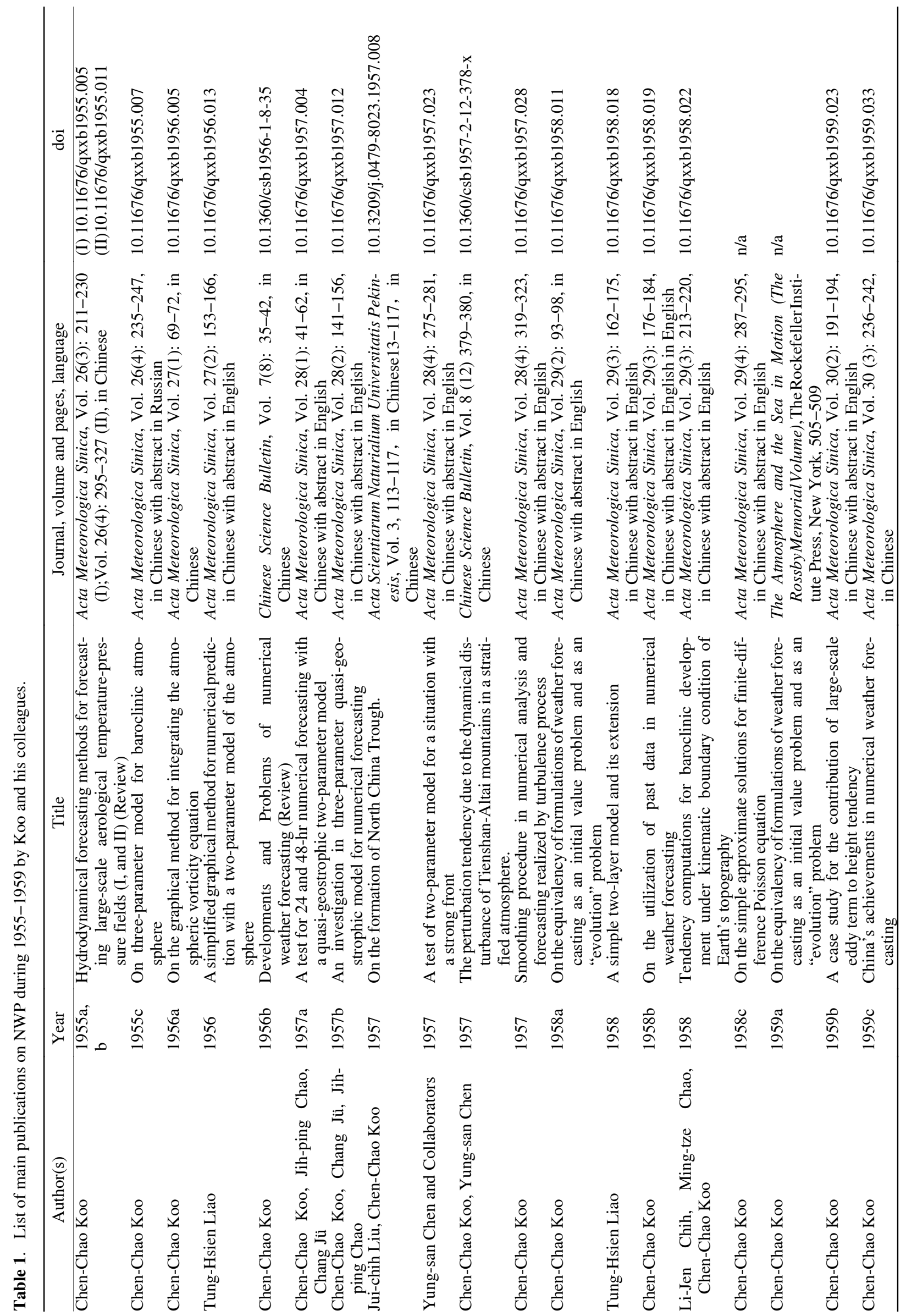


Although progress was interrupted for nearly a decade after 1966, the young scientists influenced by Chen-Chao Koo formed a strong personnel basis for the development of numerical weather and climate models in China since the mid1970s. Readers may refer to Zeng (1979b), Meng et al. (2019), and Yu et al. (2019) for reviews on the development of numerical models since the 1970s in China.

During 3-7 June 1957, just two months before Rossby's sudden passing, Koo attended a conference on numerical weather forecasting organized by Bert Bolin on behalf of the International Meteorological Institute in Stockholm University. Rossby, Charney, Obukhov, Lorenz, Smargorinsky, Fjørtoft, Hinkelmann, and Wiin-Nielsen were among the attendees of the conference. There was a special seminar on the evening of June 4 where Koo reported on the recent progress in meteorological research conducted in China which impressed the attendees of the conference very much (Koo, 1957a). Indeed, the NWP research led by Chen-Chao Koo in China during the 1950s and later NWP development not only exemplified Rossby's expectation that "during the next few years, an extremely vigorous development of Chinese meteorology and, as a result, many significant realistic contributions from that part of world" (Rossby, 1951), but also illustrated the pivotal importance of the internationalism (Persson, 2005a) that Rossby had always been promoting in the development of modern atmospheric sciences all over the world (see Fig. 3).

Table 2. A brief biographic sketch of Chen-Chao Koo.

A brief biographic sketch of Chen-Chao Koo

1920. 9. 19 Born in Shanghai

1938. 11-1942. 7 Department of Mathematics Physics and then Department of Geography of The National Central University

1943. 10-1945. 6 Graduate School of The National SouthWest Associated University

1945. 7-1947. 10 Assistant Scientist, Institute of Meteorology, Academia Sinica

1947. 11-1950. 3 Department of Meteorology, Stockholm University, C.G. Rossby as supervisor

1950. 4-1950. 5 Return to China before obtaining his Ph.D. degree in Stockholm University

1950. 6-end of 1955 Associate Research Scientist, Institute of Geophysics and Meteorology (IGM) in Chinese Academy of Sciences, during this period also the Director of Joint Center for Weather Analysis and Forecasting under the China's Meteorological Administration.

1956-1966, Senior Scientist, Institute of Geophysics and Meteorology in Chinese Academy of Sciences, one of two directors (another director was T.C. Yeh) of the Laboratory for Synoptic and Climate Research, leading the research in numerical weather forecasting, atmospheric physics, and also atmospheric dynamics.

1966. 6-1968. 3, Deputy Director, Institute of Applied Geophysics, Chinese Academy of Sciences.

1968. 3-1976. 3. 27, Senior Scientist and Director-general (since 1973. 4), Institute of Atmospheric Physics, Chinese Academy of Sciences.

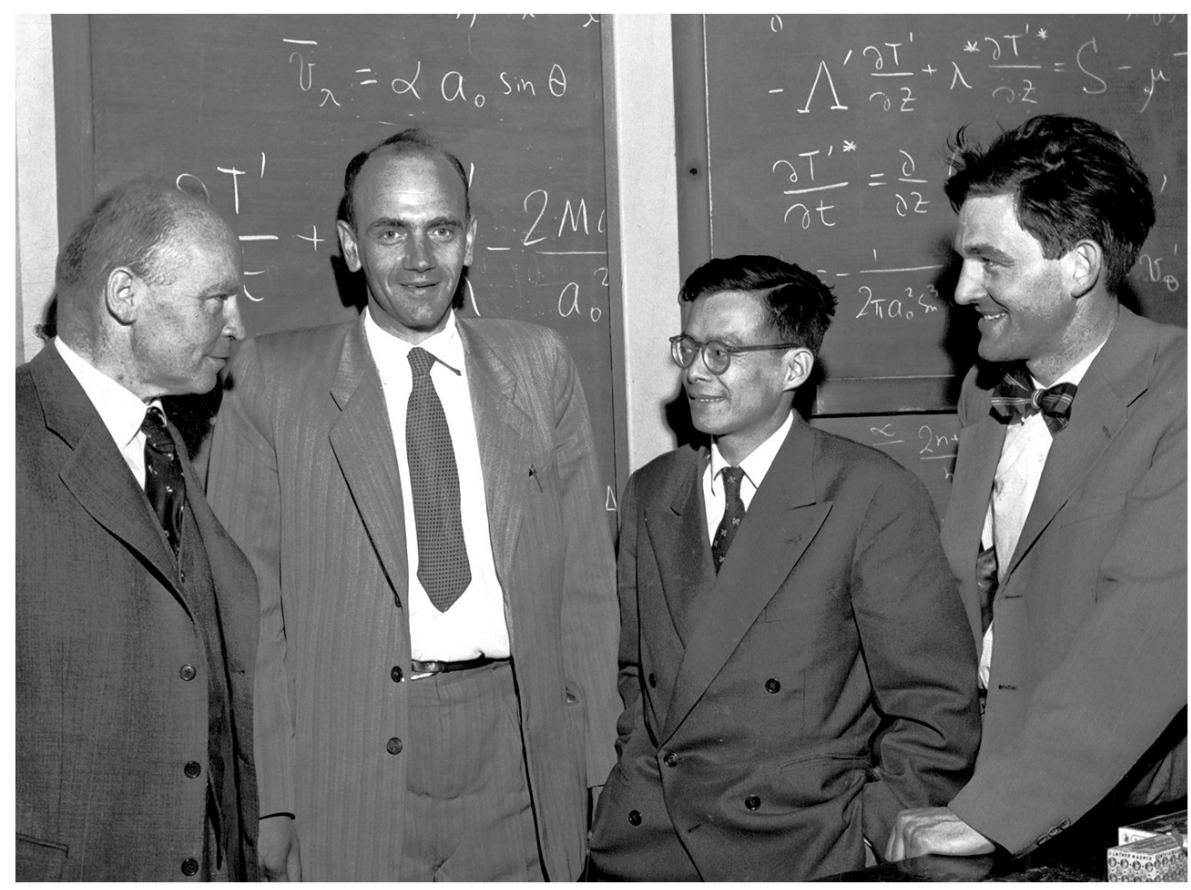

Fig. 3. Chen-Chao Koo during the NWP conference held at Stockholm University during 3-7 June 1957. From left: C.-G. Rossby, A. M. Obukhov, C.-C. Koo, and Bert Bolin. (copyright: $\mathrm{SvD} / \mathrm{TT})$. 
Acknowledgements. The original titles, and the authors' names in Chinese, of the papers by Koo's NWP team are included in the supplemental material (Fig. S1) as a reference for readers who may read Chinese. The author is indebted to Professors Li-Ren Ji, Ji-Ping Chao, and Yong-Ti Zhu for providing useful information on the early NWP experiments in China. Dr. Anders Persson kindly provided the information on Koo's visit to Stockholm in 1957 and helped the author in getting the license for using the valuable picture of Rossby, Obukhov, Koo, and Bolin from SvD/TT. The support provided by the National Natural Science Foundation of China (Grant No. 42042011) is appreciated.

Electronic supplementary material: Supplementary material is available in the online version of this article at http://doi.org/ 10.1007/s00376-021-0268-y.

\section{REFERENCES}

Bauer, P., A. Thorpe, and G. Brunet, 2015: The quiet revolution of numerical weather prediction. Nature, 525, 47-55, https://doi.org/10.1038/nature14956.

Bengtsson, L., and Coauthors, 2015: The Meteorological Auto Code (MAC) and Numerical Weather Prediction (NWP) at SMHI. Report Meteorology and Climatology, No. 117, Stockholm, Sweden. [Available from https://www.smhi.se/polopoly_fs/1. 102780!/RMK_117.pdf]

Benjamin, S. G., J. M. Brown, G. Brunet, P. Lynch, K. Saito, and T. W. Schlatter, 2018: 100 years of progress in forecasting and NWP applications. Meteor. Monogr., 59, 13.1-13.67, https://doi.org/10.1175/AMSMONOGRAPHS-D-18-0020.1.

Blumen, W., and W. M. Washington, 1973: Atmospheric dynamics and Numerical Weather Prediction in the People's Republic of China 1949-1966. Bull. Amer. Meteor. Soc., 54, 502-518, https://doi.org/10.1175/1520-0477(1973)054<0502:ADANWP> 2.0.CO;2.

Bolin, B., Ed., 1959: The Atmosphere and the Sea in Motion-The Rossby Memorial Volume. The Rockefeller Institute Press, New York, $509 \mathrm{pp}$.

Charney, J. G., 1949: On a physical basis for numerical prediction of large-scale motions in the atmosphere. J. Meteorol., 6, 372-385, https://doi.org/10.1175/1520-0469(1949)006<0372:OAPBFN>2.0.CO;2.

Charney, J. G., and A. Eliassen, 1949: A numerical method for predicting the perturbations of the middle latitude westerlies. Tellus, 1, 38-54, https://doi.org/10.3402/tellusa.v1i2.8500.

Charney, J. G., and N. A. Phillips, 1953: Numerical integration of the quasi-geostrophic equations for barotropic and simple baroclinic flows. J. Meteorol., 10, 71-99, https://doi.org/10.1175/1520-0469(1953)010<0071:NIOTQG>2.0.CO;2.

Charney, J. G., R. Fjørtoft, and J. von Neumann, 1950: Numerical integration of the barotropic vorticity equation. Tellus, 2, 237-254, https://doi.org/10.3402/tellusa.v2i4.8607.

Chen, Y.-S., R. Z. Liu, Y. F. Xu, L. R. Ji, and C. C. Koo, 1957: A test of two-parameter model for a situation with a strong front. Acta Meteorologica Sinica, 28(4), 275-281, https://doi.org/10.11676/qxxb1957.023. (in Chinese with English abstract)

Chih, L.-J., M.-T. Chao, and C.-C. Koo, 1958: Tendency computations for baroclinic development under kinematic boundary condition of Earth's topography. Acta Meteorologica Sinica, 29(3), 213-220, https://doi.org/10.11676/qxxb1958.022. (in Chinese with English abstract)

Chou, G.-F., 1974: A problem of using past data in numerical weather forecasting. Scientia Sinica, 17(6), 814-825, https://doi.org/10.1360/ya1974-17-6-814.

Chu, Y. T., 1961: A three-level nonlinear prediction model in spherical coordinates. Acta Meteor. Sinica, 31(3), 216-233.

Eliassen, A., 1952: Symposium on numerical forecasting: Simplified dynamic models of the atmosphere, designed for the purpose of numerical weather prediction. Tellus, 4, 145-156, https://doi.org/10.3402/tellusa.v4i3.8778.

Fjørtoft, R., 1952: On a numerical method of integrating the baratropic vorticity equation. Tellus, 4, 179-194, https://doi.org/10.1111/j.2153-3490.1952.tb01003.x.

Harper, K. C., 2008: Weather by the Numbers: The Genesis of Modern Meteorology. MIT Press, 308 pp.

Kibel, I. A., 1957: Introduction to the Hydrodynamic Method of Short-Range Weather Prognosis. Gosud. Izdat. Tek.-Teor. Lit., Moscow, 375 pp. (in Russian)

Koo, C.-C., 1950: An iterative relation of the influence function in numerical forecasting. J. Meteorol., 7, 163-164, https://doi.org/10.1175/1520-0469(1950)007<0163:AIROTI>2.0.CO;2.

Koo, C.-C., 1955a: Hydrodynamical forecasting methods for forecasting large-scale aerological temperature-pressure fields. I. Acta Meteorologica Sinica, 26(3), 211-230, https://doi.org/10.11676/qxxb1955.005. (in Chinese)

Koo, C.-C., 1955b: Hydrodynamical forecasting methods for forecasting large-scale aerological temperature-pressure fields. II. Acta Meteorologica Sinica, 26(4), 295-327, https://doi.org/10.11676/qxxb1955.011. (in Chinese)

Koo, C.-C., 1955c: On three-parameter model for baroclinic atmosphere. Acta Meteorologica Sinica, 26(4), 235-247, https://doi.org/10.11676/qxxb1955.007.

Koo, C.-C., 1956a: On the graphical method for integrating the atmospheric vorticity equation. Acta Meteorologica Sinica, 27(1), 69-72, https://doi.org/10.11676/qxxb1956.005. (in Chinese)

Koo, C.-C., 1956b: Developments and Problems of numerical weather forecasting (Review). Chinese Science Bulletin, 7(8), 35-42, https://doi.org/10.1360/csb1956-1-8-35. (in Chinese)

Koo, C.-C., 1957a: Report on the numerical weather forecasting symposium held in Stockholm. Chinese Science Bulletin, 8, 480, https://doi.org/10.1360/csb1957-2-15-480. (in Chinese) 
Koo, C.-C., 1957b: Smoothing procedure in numerical analysis and forecasting realized by turbulence process. Acta Meteorologica Sinica, 28(4), 319-323, https://doi.org/10.11676/qxxb1957.028. (in Chinese with English abstract)

Koo, C.-C., 1958a: On the equivalency of formulations of weather forecasting as an initial value problem and as an "evolution" problem. Acta Meteorologica Sinica, 29(3), 93-98, https://doi.org/10.11676/qxxb1958.011. (in Chinese with English abstract)

Koo, C.-C., 1958b: On the utilization of past data in numerical weather forecasting. Acta Meteorologica Sinica, 29(3), 176-184, https://doi.org/10.11676/qxxb1958.019. (in Chinese with English abstract)

Koo, C.-C., 1958c: On the simple approximate solutions for finite-difference Poisson equation. Acta Meteorologica Sinica, 29(4), 287-295.

Koo, C.-C., 1959a: On the equivalency of formulations of weather forecasting as an initial value problem and as an "evolution" problem. The Atmosphere and the Sea in Motion (The Rossby Memorial Volume). The Rockefeller Institute Press, New York, 505-509.

Koo, C.-C., 1959b: A case study for the contribution of large-scale eddy term to height tendency. Acta Meteorologica Sinica, 30(3), 191-194, https://doi.org/10.11676/qxxb1959.023. (in Chinese with English abstract)

Koo, C.-C., 1959c: China's achievements in numerical weather forecasting. Acta Meteorologica Sinica, 30(3), 236-242, https://doi.org/10.11676/qxxb1959.033. (in Chinese)

Koo, C.-C., 1962: Cybernetic aspects of atmospheric processes. Scientia Sinica, 11(2), 259-274, https://doi.org/10.1360/ya1962-11-2259.

Koo, C.-C., and Y. S. Chen, 1957: The perturbation tendency due to the dynamical disturbance of Tienshan-Altai mountains in a stratified atmosphere. Chinese Science Bulletin, 8(12), 378-379, https://doi.org/10.1360/csb1957-2-12-378-x. (in Chinese)

Koo, C.-C., J.-P. Chao, and C. Jü, 1957a: A test for 24 and 48-hr numerical forecasting with a quasi-geostrophic two-parameter model. Acta Meteorologica Sinica, 28(1), 41-62, https://doi.org/10.11676/qxxb1957.004. (in Chinese with English abstract)

Koo, C.-C., C. Jü, and J.-P. Chao, 1957b: An investigation in three-parameter quasi-geostrophic model for numerical forecasting. Acta Meteorologica Sinica, 28(3), 141-156, https://doi.org/10.11676/qxxb1957.012. (in Chinese with English abstract)

Koo, C.-C., and Coauthors, 1961: Papers in Dynamical Meteorology. Memoir of the Institute of Geophysics and Meteorology, Chinese Academy of Sciences, 106 pp. (in Chinese)

Lewis, J., and S. Lakshmivarahan, 2008: Sasaki's pivotal contribution: Calculus of variations applied to weather map analysis. Mon. Wea. Rev., 136, 3553-3567, https://doi.org/10.1175/2008MWR2400.1.

Liao, T.-H., 1956: A simplified graphical method for numerical prediction with a two-parameter model of the atmosphere. Acta Meteorologica Sinica, 27(3), 153-166, https://doi.org/10.11676/qxxb1956.013. (in Chinese with English abstract)

Liao, T.-H., 1958: A simple two-layer model and its extension. Acta Meteorologica Sinica, 29(3), 162-175, https://doi.org/10. 11676/qxxb1958.018. (in Chinese with English abstract)

Liu, J.-C., and C. C. Koo, 1957: On the formation of North China Trough. Acta Scientiarum Naturialium Universitatis Pekinesis, 3, 107-113, https://doi.org/10.13209/j.0479-8023.1957.008. (in Chinese)

Lu, J. H., and T. Schneider, 2017: Evolving perspectives on abrupt seasonal changes of the general circulation. Adv. Atmos. Sci., 34(10), 1185-1194, https://doi.org/10.1007/s00376-017-7068-4.

Meng, Z. Y., and Coauthors, 2019: Review of Chinese atmospheric science research over the past 70 years: Synoptic meteorology. Science China Earth Sciences, 62, 1946-1991, https://doi.org/10.1007/s11430-019-9534-6.

Persson, A., 2005a: Early operational numerical weather prediction outside the USA: An historical introduction. Part 1: Internationalism and engineering NWP in Sweden, 1952-69. Meteorological Applications, 12, 135-159, https://doi.org/10.1017/S1350 482705001593.

Persson, A., 2005b: Early operational numerical weather prediction out- side the USA: An historical introduction: Part II: Twenty countries around the world. Meteorological Applications, 12, 269-289, https://doi.org/10.1017/S1350482705001751.

Persson, A., 2005c: Early operational numerical weather prediction outside the USA: An historical introduction Part III: Endurance and mathematics-British NWP, 1948-1965. Meteorological Applications, 12, 381-413, https://doi.org/10.1017/S1350482705001933.

Phillips, N. A., 1951: A simple three-dimensional model for the study of large-scale extratropical flow patterns. J. Meteorol., 8, 381-394, https://doi.org/10.1175/1520-0469(1951)008<0381:ASTDMF>2.0.CO;2.

Phillips, N., W. Blumen, and O. Coté, 1960: Numerical weather prediction in the Soviet Union. Bull. Amer. Meteor. Soc., 41, 599-617, https://doi.org/10.1175/1520-0477-41.11.599.

Randall, D. A., and Coauthors, 2018: 100 years of Earth system model development. Meteor. Monogr., 59, 12.1-12.66, https://doi.org/10.1175/AMSMONOGRAPHS-D-18-0018.1.

Rossby, C. G., 1951: Note on cooperative research projects. Tellus, 3, 212-216, https://doi.org/10.1111/j.2153-3490.1951.tb00801.x.

Sasaki, Y., 1970: Some basic formalisms in numerical variational analysis. Mon. Wea. Rev., 98, 875-883, https://doi.org/10.1175/15200493(1970)098<0875:SBFINV>2.3.CO;2.

Tseng, Q.-T. (Zeng, Q. C.), 1961: The application of a complete system of thermo-hydrodynamic equations to short-term weather forecast in a two-level model. Dokl. Akad. Nauk. SSSR, 137, 76-78.

Yu, R. C., Y. Zhang, J. J. Wang, J. Li, H. M. Chen, J. D. Gong, and J. Chen, 2019: Recent progress in numerical atmospheric modeling in China. Adv. Atmos. Sci., 36(9), 938-960, https://doi.org/10.1007/s00376-019-8203-1.

Zeng, Q.-C., 1979a: The Mathematical and Physical Basis of Numerical Weather Prediction, Volume I. Science Press, 543 pp. (in Chinese)

Zeng, Q.-C., 1979b: The advance in atmospheric dynamics and numerical weather prediction in China. Scientia Atmospherica Sinica, 3, 256-269, https://doi.org/10.3878/j.issn.1006-9895.1979.03.08. (in Chinese with English abstract)

Zhou, X. P., 2006: Kaituo Fengxian, Keji Kaimo - Jinian Zhuming Daqi Kexuejia Gu Zhenchao (The Chen-Chao Koo Memorial Volume). Meteorological Press, 413 pp. (in Chinese) 